03

\title{
Определение температуры газов при прохождении через них водного аэрозоля
}

\author{
() И.С. Войтков, Г.В. Кузнецов, П.А. Стрижак \\ Национальный исследовательский Томский политехнический университет \\ ๑ E-mail: pavelspa@tpu.ru
}

Поступило в Редакцию 14 октября 2016 г.

Представлены результаты экспериментальных исследований процессов изменения температуры газов при импульсном впрыске аэрозоля воды, раствора $\mathrm{NaCl}$ и суспензии глины. Начальная температура газов составляла $520-910 \mathrm{~K}$. Использованы аэрозоли с размерами капель от 40 до $400 \mu \mathrm{m}$. Для визуализации движения последних во встречном потоке продуктов сгорания использованы панорамные оптические методы. Установлено влияние на процесс охлаждения газов дисперсности аэрозоля, концентрации $\mathrm{NaCl}$ и глины в растворах и суспензиях, а также условий впрыска жидкости.

DOI: 10.21883/PJTF.2017.06.44403.16525

Исследования физических и химических процессов, а также фазовых превращений, протекающих при взаимодействии огнетушащих веществ и материалов с очагами возгораний и пожаров [1-3], позволяют сделать заключение о том, что задачи борьбы с пламенем в зоне горения и непосредственно очагами термического разложения целесообразно разделять. Наибольшую эффективность борьбы с пожарами можно обеспечить при создании специфических условий как снижения температуры в зоне горения, так и прекращения термического разложения горючих веществ и материалов [1-3]. Снижение температуры в зоне горения при тушении любого пожара (особенно лесного) представляет первостепенную задачу, так как ее решение позволяет существенно упростить борьбу с очагом возгорания в целом. Предложенная по результатам экспериментов [4,5] и моделирования [6,7] технология применения распределенных во времени и пространстве капельных потоков жидкостей, эмульсий и суспензий ориентирована на максимальное снижение температуры в зоне горения за счет поглощения теплоты ис- 
парения. Однако до настоящего времени не исследованы в полной мере механизмы физических процессов, определяющих динамику снижения температуры, и не определены характерные времена ее восстановления после прохождения через пламя водных аэрозолей.

Использование известных моделей тепломассопереноса $[8,9]$ для изучения условий теплообмена капель жидкости (в частности, воды) с газовой средой не позволяет в полной мере определить характеристики испарения при температуре газов более $600 \mathrm{~K}[10]$. Использование балансных соотношений вида $Q_{e} W_{e}=\alpha\left(T_{g}-T_{s}\right)\left(Q_{e}\right.$ - теплота парообразования, $\mathrm{J} / \mathrm{kg} ; W_{e}-$ массовая скорость испарения, $\mathrm{kg} /\left(\mathrm{m}^{2} \cdot \mathrm{c}\right) ; \alpha-$ коэффициент теплообмена, $\mathrm{W} /\left(\mathrm{m}^{2} \cdot \mathrm{K}\right) ; T_{g}, T_{s}$ - температуры газов и поверхности капли, K) на основании предположения о том, что вся подведенная к поверхности капли жидкости энергия расходуется на ее испарение $[8,9]$, приводит к значениям скоростей испарения, в несколько раз отличающимся от экспериментальных [10]. Поэтому в случае применения выражений Рэнца-Маршала вида $\mathrm{Nu}=2+0.6 \operatorname{Re}^{1 / 2} \operatorname{Pr}^{1 / 3}$ (Nu, Re, Pr - числа Нуссельта, Рейнольдса, Прандтля) [8,9] сложно прогнозировать условия и характеристики теплообмена в зоне горения (температура может достигать $1200-1500 \mathrm{~K}$ ) при подаче капельных потоков жидкостей. Результаты моделирования $[6,7]$ показали, что температуру в зоне горения можно довольно существенно (на несколько сотен градусов) снизить даже при импульсной подаче малых (менее $1 \mathrm{~mm})$ групп капель $(2-5 \mathrm{pcs})$. При этом выдвинута гипотеза $[6,7]$ о том, что в большей мере снижение $T_{g}$ определяется эндотермическими фазовыми превращениями, а не условиями охлаждения газов за счет теплообмена с жидкостью и аккумуляцией теплоты. Целесообразно, кроме анализа изменения $T_{g}$, сравнить времена сохранения пониженных температур газов после прохождения через них аэрозольных потоков (важны такие оценки для условий высоких начальных температур газов, в частности, продуктов сгорания).

Цель работы - экспериментальное определение характеристик процесса изменения температуры продуктов сгорания после прохождения через них аэрозоля жидкости.

Для генерации аэрозоля применялись: емкость с жидкостью под давлением 100-300 $\mathrm{kPa}$ и распылительная форсунка (радиусы капель $R_{d}=40-400 \mu \mathrm{m}$, концентрация $\gamma \approx 3 \cdot 10^{-5} \mathrm{~m}^{3} \mathrm{drops} / \mathrm{m}^{3}$ gas, длительность импульса $1 \mathrm{~s})$. Использовались: дистиллированная вода, раствор

4 Письма в ЖТФ, 2017, том 43, вып. 6 
$\mathrm{NaCl}$ (частицы размерами менее $10 \mu \mathrm{m}$ растворялись в воде аналогично опытам $[4,5])$, суспензия глины (частицы размерами менее $5 \mu \mathrm{m}$ ).

Для создания потока высокотемпературных продуктов сгорания применялись полый цилиндр (высота $-1 \mathrm{~m}$, внутренний диаметр $0.2 \mathrm{~m})$ из жаропрочного кварцевого стекла и горелка $[4,5]$ в форме цилиндра (высота $-0.1 \mathrm{~m}$, внутренний и внешний диаметры -0.15 и $0.19 \mathrm{~m}$ ). В каждом эксперименте внутреннее пространство горелки заполнялось керосином в объеме $250 \mathrm{ml}$. Инициировалось его зажигание. В трех (по высоте) точках $(0.3,0.6,0.9 \mathrm{~m})$ цилиндра размещались хромель-алюмелевые термопары (диапазон измеряемых температур $273-1473 \mathrm{~K}$, погрешность $\pm 3 \mathrm{~K}$, инерционность не более $0.1 \mathrm{~s}$ ). За счет регулирования притока воздуха в горелку выдерживалось идентичное начальное температурное поле газов. Температура продуктов сгорания изменялась в среднем от $910 \mathrm{~K}$ (у основания горелки) до $520 \mathrm{~K}$ (на выходе из цилиндра с газами). После достижения требуемых начальных температур газов осуществлялся впрыск аэрозоля во внутреннюю полость цилиндра. Регистрировались изменения температуры парогазовой смеси в точках расположения термопар $\left(T_{g}^{\prime}\right)$, а также положение аэрозольного облака.

Применение для определения температуры газов трех термопар обеспечивало возможность в каждом эксперименте контролировать начальную (до впрыска аэрозоля) температуру газов в соответствующих сечениях канала $(910 \pm 15,690 \pm 10,520 \pm 7 \mathrm{~K})$. Определялись изменения температур $\left(\Delta T_{g}=T_{g}-T_{g}^{\prime}\right)$ относительно начальных $T_{g}$ (до момента прохождения каплями сечений с термопарами). Контроль $\Delta T_{g}$ позволял вычислить времена сохранения пониженных температур $(\tau)$ газов после прохождения аэрозоля. Систематическая погрешность определения $\tau$ не превышала $1 \mathrm{~s}$.

Основные средства высокоскоростной кросскорреляционной видеорегистрации аналогичны применяемым в опытах $[4,5]$. Слежение за перемещающимися каплями (для определения границы раздела сред при вычислении времен $\tau$, которые в работах [6,7] обозначены как „времена сохранения температурного следа капель“) проводилось с применением программного обеспечения Tema Automotive $[4,5]$. Зоной пониженных температур газов считалась область с температурой $T_{g}^{\prime}$ ниже начальной $T_{g}$ не менее чем на $10 \mathrm{~K}$. Скорости и траектории перемещения объектов регистрации определялись с применением панорамных методов (PIV, PTV, IPI, SP) [4,5]. Систематические погрешности 


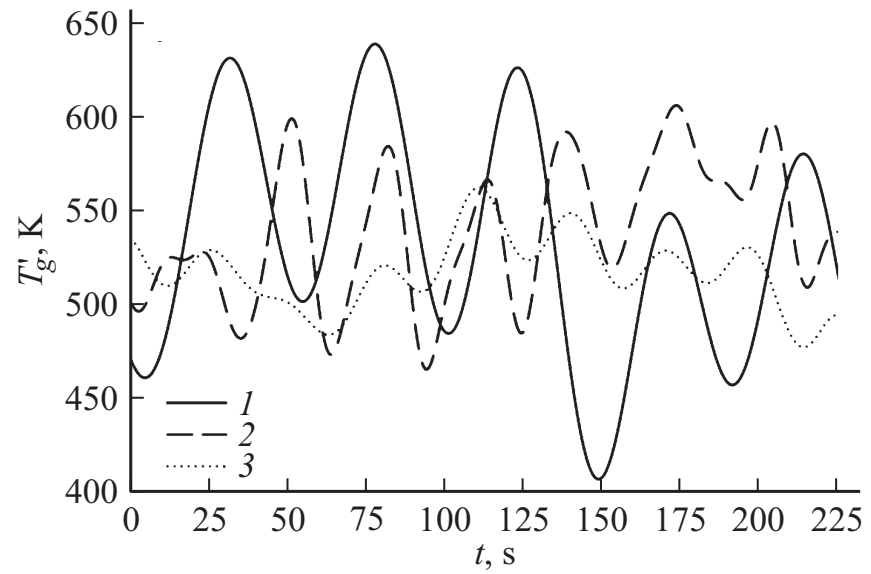

Рис. 1. Графики изменения температуры газов после прохождения через них аэрозоля воды (1), раствора $\mathrm{NaCl}$ (2) и суспензии глины (3) при размерах капель $R_{d}=0.06-0.18 \mathrm{~mm}$.

определения размеров (радиусов) $R_{d}$ и скоростей перемещения $U_{d}$ капель составили 3.2 и $2.5 \%$. Средняя скорость движения продуктов сгорания $U_{g}$ в цилиндре была около $1.5 \mathrm{~m} / \mathrm{s}$.

На рис. 1 приведены зависимости, иллюстрирующие изменение температуры газов $\left(T_{g}^{\prime}\right)$ при прохождении через них аэрозоля. Максимальные значения температуры соответствуют моменту импульсного впрыска капель $\left(T_{g}^{\prime} \approx T_{g}\right)$. Эксперименты показали, что время движения аэрозоля от верхнего входного сечения канала с газами до первой термопары составляло около $0.14 \mathrm{~s}$, второй $-0.19 \mathrm{~s}$, третьей $-0.28 \mathrm{~s}$ (времена растут за счет торможения капель газами). Наибольшее снижение температуры $T_{g}^{\prime}$ зарегистрировано в экспериментах с водой (рис. 1), меньшее снижение $T_{g}^{\prime}$ соответствует раствору $\mathrm{NaCl}$.

На рис. 2 представлены зависимости времени $(\tau)$ сохранения (восстановления температуры $T_{g}^{\prime}$ до значений $T_{g}$ ) пониженных температур газов после впрыска аэрозоля воды, раствора $\mathrm{NaCl}$ и суспензии глины при разных начальных размерах капель. Видно, что чем больше $R_{d}$, тем более длительное время сохраняются пониженные температуры $T_{g}^{\prime}$. Полученный результат обусловлен тем, что уменьшение $R_{d}$ приводило

4* Письма в ЖТФ, 2017, том 43, вып. 6 


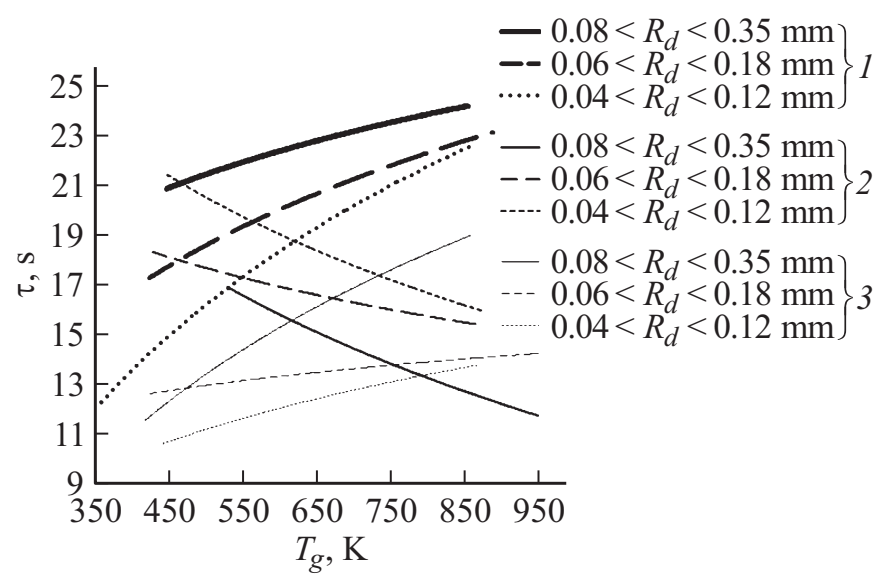

Рис. 2. Аппроксимационные значения времен сохранения пониженных температур газов после прохождения аэрозоля воды (1), раствора $\mathrm{NaCl}$ (2) и суспензии глины (3) при разных размерах капель и начальной температуре газов.

к росту скорости испарения [4,5] и соответственно интенсивности вдува паров во внешнюю по отношению к каплям среду. Как следствие, возрастала сила сопротивления, обусловленная движением встречного газового потока. Капли разворачивались и двигались в обратном направлении.

Установлено (рис. 2), что для капель раствора $\mathrm{NaCl}$ характерно явно выраженное снижение значений $\tau$ с ростом начальных температур газов (особенно выше $650 \mathrm{~K}$ ). При этом изменяется наклон кривых $\tau\left(T_{g}\right)$ на рис. 2 в противоположную (относительно воды) сторону. Также меняется их расположение относительно друг друга при сравнении размеров капель. Такой эффект можно объяснить с использованием результатов опытов [5]. С ростом массовой доли $\mathrm{NaCl}$ в растворе до $5 \%$ скорости испарения капель (характеризуются параметром $\Delta R[5]$ ) снижаются на $10-20 \%$ [5]. Образуется меньшее количество паров. Влияние данного механизма снижения температуры газов становится менее значимым. Очевидно, что при высоких температурах на величину $T_{g}^{\prime}$ определяющее влияние оказывает скорость испарения, которая для капель воды с примесью $\mathrm{NaCl}$ существенно ниже [5].

Письма в ЖТФ, 2017, том 43, вып. 6 


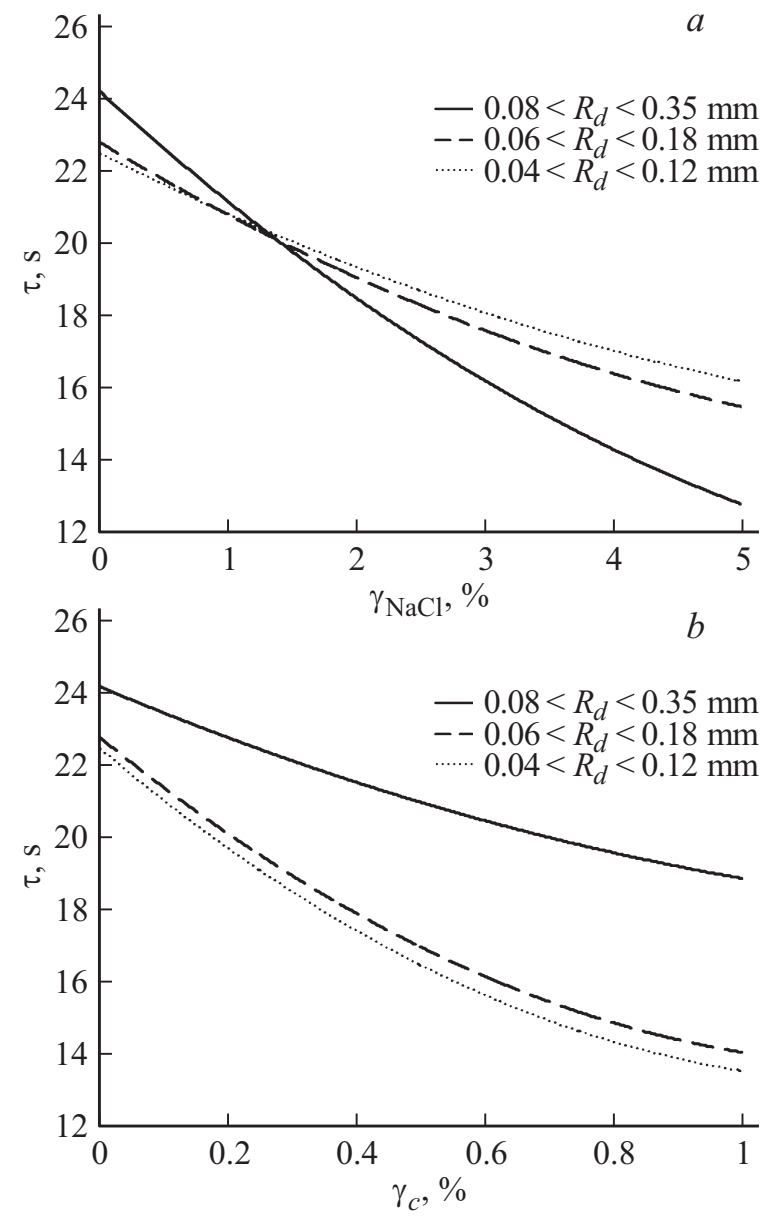

Рис. 3. Аппроксимационные значения времен сохранения пониженных температур газов (начальное значение $T_{g} \approx 850 \mathrm{~K}$ ) после прохождения аэрозоля при разных размерах капель, концентрации $\mathrm{NaCl}(a)$ и частиц глины $(b)$.

В то же время при относительно умеренных температурах газов (менее $600 \mathrm{~K}$ ) зарегистрированы практически сопоставимые значения $\tau$ для воды и раствора $\mathrm{NaCl}$ (рис. 2). Это связано с тем, что при таких $T_{g}$

Письма в ЖТФ, 2017, том 43, вып. 6 
капли при прохождении ими канала (времена составили менее $0.5 \mathrm{~s}$ ) не успевают прогреться до температур интенсивного парообразования. Испарение протекает с малой скоростью. В данном случае снижение температуры $T_{g}^{\prime}$ обеспечивается главным образом за счет аккумуляции теплоты относительно холодной жидкостью, раствором или суспензией. В этих условиях капли раствора $\mathrm{NaCl}$, скорость испарения которых меньше по сравнению с водой, способны пройти большие расстояния. По мере продвижения через продукты сгорания капли, уменьшаясь в размерах до $0.1 \mathrm{~mm}$, затормаживаются, разворачиваются и двигаются в противоположном направлении. При этом капли, поверхность которых уже предварительно нагрета до температур интенсивного парообразования, продолжают испаряться. Мелкие $\left(R_{d}=0.04-0.12 \mathrm{~mm}\right)$ капли воды испаряются быстрее, чем раствора $\mathrm{NaCl}$, которые, продолжая свое движение в потоке газов, еще на некоторое время обеспечивают сохранение пониженных (относительно начальных) значений температур $T_{g}$. Поэтому при низких $T_{g}$ (менее $600 \mathrm{~K}$ ) времена $\tau$ для раствора $\mathrm{NaCl}$ превышают аналогичные значения для воды на 2-5s.

При воздействии на продукты сгорания каплями суспензии глины времена $\tau$ снижались в среднем на $3-9$ s по сравнению с аналогичными значениями для воды. При добавлении частиц глины в капли воды интенсивность прогрева последних и испарения значительно возрастала. Известно [4], что добавление твердых частиц различных материалов приводит к интенсификации прогрева суспензии по сравнению с водой. Этот фактор приводил к росту скоростей парообразования и увеличению расходуемой на испарение энергии. Но после испарения пленки жидкости с поверхности частичек глины последние нагревались за счет кондуктивного, конвективного и лучистого теплообмена с газами (за счет большей теплопроводности, температуропроводности и поглощения излучения частички глины прогревались быстрее воды; вокруг них, в отличие от капель, не формировался слой паров, существенно замедляющий движение и снижающий конвективные тепловые потоки). Температура газов после прохождения через них аэрозоля суспензии увеличивалась относительно опытов с водой. С ростом концентраций частиц глины и $\mathrm{NaCl}$ выделенные особенности становились более выраженными (рис. 3).

Таким образом, эксперименты показали определяющую роль процесса испарения при формировании температурного поля газов после прохождения через них аэрозоля. Выделенные особенности для воды,

Письма в ЖТФ, 2017, том 43, вып. 6 
а также раствора и суспензии на ее основе показали специфику применения разных составов для снижения температуры в зоне горения.

Исследование выполнено за счет гранта Российского научного фонда (№ 14-39-00003).

\section{Список литературы}

[1] Коробейничев О.П., Шмаков А.Г., Чернов А.А. и др. // ФГВ. 2010. Т. 46. № 1. C. 20-25.

[2] $W u W$., Yang L., Gong J. et al. // J. Fire Sci. 2011. V. 29. N 5. P. 465-475.

[3] Korobeinichev O.P., Shmakov A.G., Shvartsberg V.M. et al. // Fire Safety J. 2012. V. 51. P. 102-109.

[4] Vysokomornaya O.V., Kuznetsov G.V., Strizhak P.A. // Fire Saf. J. 2014. V. 70. P. 61-70.

[5] Волков Р.С., Кузнецов Г.В., Стрижак П.А. // Письма в ЖТФ. 2015. Т. 41. B. 20. C. 103-110.

[6] Strizhak P.A. // J. Eng. Phys. Thermophys. 2013. V. 86. N 4. P. 895-904.

[7] Кузнецов Г.В., Стрижак П.А. // ПМТФ. 2015. Т. 56. № 4. С. 1-13.

[8] Терехов В.И., Терехов В.В., Шишкин Н.Е., Би К.Ч. // ИФЖ. 2010. Т. 83. № 5. С. 829-836.

[9] Терехов В.И., Пахомов М.А. Тепломассоперенос и гидродинамика в газокапельных потоках. Новосибирск: Изд-во НГТУ, 2009.

[10] Высокоморная О.В., Кузнецов Г.В., Стрижак П.А. // ИФЖ. 2016. Т. 89. № 1. C. 133-142.

Письма в ЖТФ, 2017, том 43, вып. 6 